\title{
Additive Nano-Lithography with Focused Soft X-rays: Basics, Challenges, and Opportunities
}

\author{
Andreas Späth \\ Friedrich-Alexander-University Erlangen-Nuremberg, Physical Chemistry II, Egerlandstraße 3, \\ 91058 Erlangen, Germany; andreas.spaeth@fau.de
}

Received: 9 November 2019; Accepted: 29 November 2019; Published: 30 November 2019

\begin{abstract}
Focused soft X-ray beam induced deposition (FXBID) is a novel technique for direct-write nanofabrication of metallic nanostructures from metal organic precursor gases. It combines the established concepts of focused electron beam induced processing (FEBIP) and X-ray lithography (XRL). The present setup is based on a scanning transmission X-ray microscope (STXM) equipped with a gas flow cell to provide metal organic precursor molecules towards the intended deposition zone. Fundamentals of X-ray microscopy instrumentation and X-ray radiation chemistry relevant for FXBID development are presented in a comprehensive form. Recently published proof-of-concept studies on initial experiments on FXBID nanolithography are reviewed for an overview on current progress and proposed advances of nanofabrication performance. Potential applications and advantages of FXBID are discussed with respect to competing electron/ion based techniques.
\end{abstract}

Keywords: direct-write nanofabrication; additive nanofabrication; X-ray lithography; X-ray microscopy

\section{Introduction}

Several recent studies have demonstrated that focused electron beam induced processing (FEBIP) has high potential for the controlled bottom-up fabrication of metallic 3D nanostructures [1-14]. Furthermore, the basic processes during FEBIP are understood to more and more detail leading to developments towards more diverse, cleaner and more defined deposits for various potential applications [7,15-18]. The method employs a focused electron beam to induce local dissociation of surface-absorbed metal organic precursor molecules supplied from the gas-phase. While the dissociation products containing the metal center of the initial complex are non-volatile and will stay on the substrate, volatile portions from the ligands are pumped off by the vacuum system. Dissociation is generated mainly by low- and medium-energy secondary or backscattered electrons which have a high interaction cross-section with matter. Depending on the substrate and the chemical composition of the targeted nanostructure, several in-situ and ex-situ cleaning procedures have been developed $[14,19,20]$.

The concept of focused soft X-ray beam induced deposition (FXBID) is basically a combination of FEBIP and X-ray lithography (XRL) [21,22]. FEBIP and XRL are based on very similar fundamental principles. The radiation chemistry in XRL is also mainly caused by low-energy secondary electrons evolving from the decay processes after the initial photoexcitation [23-25]. XRL, however, is mainly targeting soft matter photoresists that are chemically altered by radiation chemistry and subsequently etched. Furthermore, standard XRL uses relatively large spot sizes and nanostructuring is typically achieved by lithography masks [26-32]. Very few studies have employed the focused beam of a scanning transmission X-ray microscope (STXM) for maskless direct-write patterning of polymer films [33-37]. Since synchrotron-based X-ray microscopes offer continuously tunable excitation photon energy, it has been shown that within a multilayer of several photoresists consecutively stacked at the same spot, each layer can be addressed separately by the resonant photon energy of the respective 
polymer resulting in 3D patterning by radiation chemistry [33,34]. The approach is limited to materials with significantly different absorption cross-sections at the chosen incident photon energies, as in transmission geometry, all layers are exposed to the beam at different degrees of focusing. However, such experiments open a completely novel perspective for complex direct-write nanofabrication. It should be mentioned that during the late 1980s and early 1990s several groups attempted to exploit broad-band synchrotron light [38-41] as well as the monochromatic X-ray beam of a photon-induced scanning Auger microscope [42,43] for additive manufacturing of metal deposits from metal organic precursors. However, due to limited instrumental capabilities, only spatially extended thin films with an optimum of some $10 \mu \mathrm{m}$ resolution could be produced [43].

FXBID exploits the photon energy-selectivity of synchrotron-based XRL and extends it by the idea of depositing metal nanostructures from suitable precursor gases [21,22]. The use of a STXM setup for these experiments offers several advantages. STXM is a raster-scanning technique which avoids the necessity of shadow masks. According to comparable results from polymer lithography the theoretical minimum feature size of the deposited metal structures is mainly determined by the spot size of the incident beam $[36,37]$. Recent developments in X-ray optics have pushed this parameter below $10 \mathrm{~nm}[44,45]$. Finally, STXM can be employed for an in-situ analysis of the metallic deposits directly after fabrication by means of resonant imaging and near-edge $X$-ray absorption fine structure (NEXAFS) spectroscopy to evaluate confinement, growth rates, oxidation state and chemical purity $[21,22,46,47]$. X-ray magnetic circular dichroism (XMCD) can be used to characterize magnetic deposits with respect to their magnetization and coercivity [48].

This review presents some basic principles of X-ray optics and X-ray microscopy as well as X-ray beam dosimetry that are relevant for FXBID experiments. In accordance, limitations, challenges and opportunities of additive nanofabrication with FXBID will be discussed with respect to the currently used STXM-based set-up, potential experimental improvements and fundamental limits. Potential applications of FXBID nanofabrication, with a special focus on porous substrates, are discussed.

\section{Things to Know about STXM and X-ray Induced Radiation Damage}

Following the development of suitable focusing optics for soft X-rays [49-51], the first soft X-ray microscopes were installed in the mid-1980s $[52,53]$. Since then, STXM has developed into a versatile method for characterization of suitably thin specimens from various scientific disciplines, such as biology, medicine, catalysis, material science, magnetism, geology, cosmology, and cultural heritage [54-64].

Figure 1 depicts a scheme of a modern STXM with all basic elements and their respective degrees of freedom $[59,65,66]$. The monochromatic X-ray beam from the synchrotron source (bending magnet or undulator) is focused by a Fresnel zone plate into a small focal spot. The incident photon energy can be tuned by adjustment of a monochromator grating in front of the microscopy setup. The innermost part the zone plate is not transmitting any light and is referred to as central stop. A proper alignment of central stop and order sorting aperture (OSA) filters undesired diffraction orders from the zone plate optics. Therefore, the OSA has to be smaller than the central stop to block non-diffracted zero order light (progressing parallel to the optical axis) and it has to be placed at an axial position far enough downstream to avoid shadowing of the first order illumination cone, but sufficiently upstream to block higher order light that has a smaller focal length and is already divergent. Presence of unintended diffraction orders with deviating focal lengths leads to aberration artefacts and unnecessary additional radiation dose. The sample is raster-scanned through the focal spot by piezo-scanners and with interferometric position control. Various detectors can be used in STXM. Usually a scintillator assisted photomultiplier tube (PMT) or a photodiode will count transmitted photons. However, also diffraction patterns [67-69] or undirected secondary radiation, such as secondary electrons [70-72] or fluorescence [73-75] can be recorded. STXMs are operated inside an (ultra)-high vacuum chamber to reduce unnecessary photon absorption within the atmosphere. 


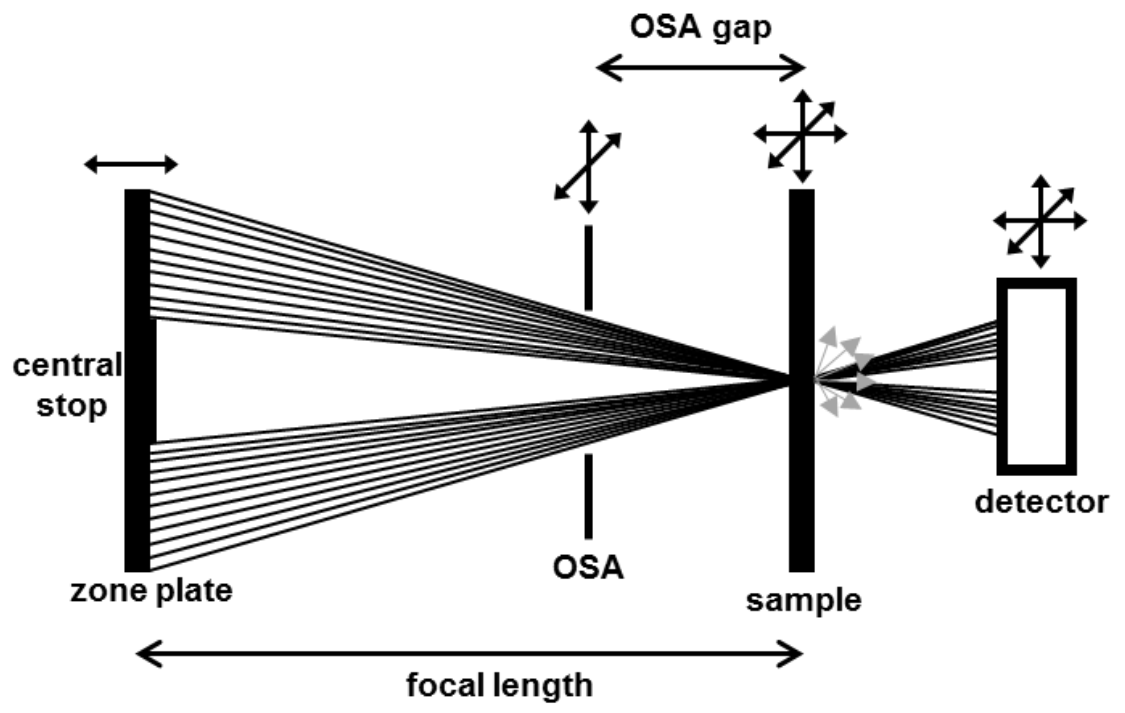

Figure 1. Scheme of main scanning transmission X-ray microscope (STXM) components and their typical degrees of freedom. The monochromatic X-ray beam is focused by a Fresnel zone plate. A proper alignment of central stop and order sorting aperture (OSA) filters undesired diffraction orders. The specimen is raster-scanned through the focal spot of the Fresnel zone plate. Signals are detected in transmission either in form of directly transmitted photons (black) or as undirected secondary radiation (gray arrows).

The heart of an X-ray microscope is the focusing optics. Extended zone plate math is provided in a comprehensible form by [76]. The most important zone plate characteristics in terms of FXBID are the minimum spot size or resolution $\Delta x$ (coherent illumination assumed), focal length $f$, and depth of focus $(D O F)$ :

$$
\begin{gathered}
\Delta x=\frac{1.22 \Delta r_{N}}{m} \\
f=\frac{4 N\left(\Delta r_{N}\right)^{2}}{\lambda \times m} \\
D O F= \pm \frac{2\left(\Delta r_{N}\right)^{2}}{\lambda \times m^{2}} .
\end{gathered}
$$

$N$ is the total number of zones and $m$ is the diffraction order (usually only the first order is employed, while higher orders are blocked by the OSA). Equation (1) shows that the spot size in STXM is mainly dependent on the outermost zone width of the applied Fresnel zone plate $\Delta r_{N}$. Since the zones also need to be placed precisely with high aspect ratios of the structures, resolution in X-ray microscopy is mainly an issue of nanofabrication $[44,45]$. It is very important that $f$ is determined by the wavelength of the incident photons in nanometers $\lambda$ and the square of the outermost zone width $\Delta r_{N}$ (Equation (2)). Higher resolutions as well as smaller photon energies both lead to shorter distances of the optics and the sample. Thus, ultra-high resolution is so far limited to photon energies above $600 \mathrm{eV}[45,77]$. The focal length is also a limiting factor for the use of higher diffraction orders $(m>1)$ for improved spatial resolution. In terms of FXBID experiments the focal length becomes important with respect to the necessity to keep the Fresnel zone plate of the microscope and the precursor gas apart. Otherwise the zone plate would be quickly covered with metal deposits. Ultra-high resolution or very small photon energies compete with the manufacturing of a gas cell sealing around the substrate [21]. The depth of focus is also directly proportional to $\Delta r_{N}$ and indirectly proportional to $\lambda$ (Equation (3)). This has to be taken into account for experiments requiring a certain axial resolution. In FXBID processes DOF might become important when free-standing 3D structures are fabricated or when 3D substrates are functionalized. 
STXM can be operated with various contrast mechanisms, but contrast based on material dependent variations in NEXAFS is most common [55,56,59]. Figure 2 presents a scheme of the NEXAFS process. For simplicity, the six electron system carbon is used instead of transition metals with more electron levels. Soft X-ray absorption leads to excitation of a core level electron into an unoccupied state. When the photon energy fits to the energetic distances of the respective energy levels, this excitation is resonant and very likely, resulting in a high absorption coefficient [55,78]. Lowest unoccupied molecular orbital (LUMO) levels are typically well-defined and yield sharp absorption peaks at the low-energy end of the NEXAFS spectrum, while energetically higher levels result in broad peaks. The exact position of the unoccupied states is dependent on the chemical state of the excited atom and, therefore, fine tuning of the excitation energy can yield a strong absorption contrast for slightly chemically different materials [55,59,72].

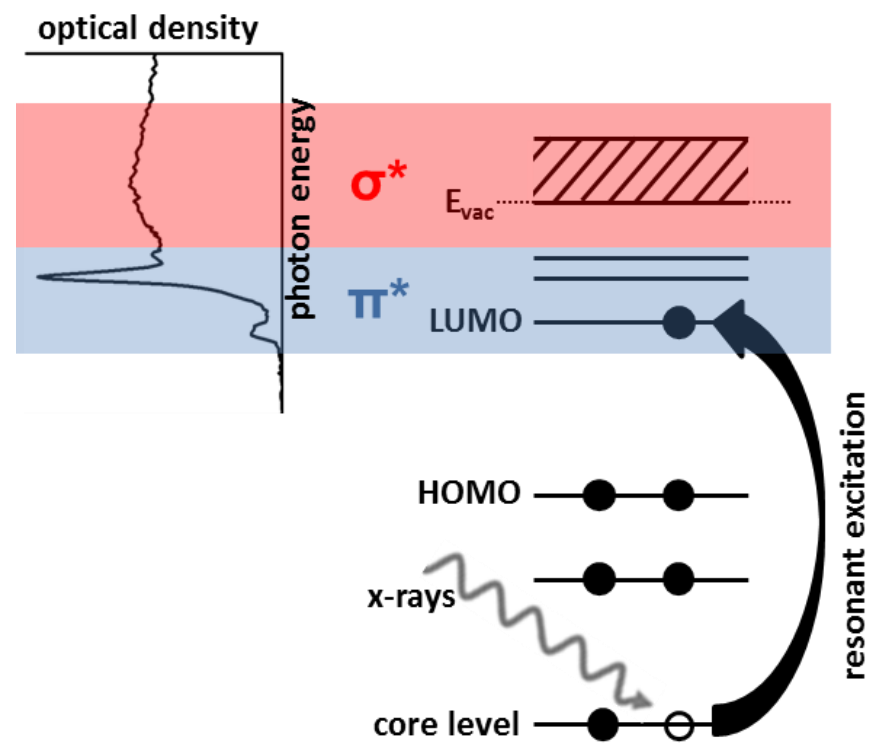

Figure 2. Schematic depiction of electron excitation induced by X-ray absorption and the generation of near-edge X-ray absorption fine structure (NEXAFS) spectra. Resonant soft X-ray illumination induces excitation of core level electrons into unoccupied states. The resulting absorption spectrum exhibits discrete resonant peaks that are a probe of the density and energy levels of respective unoccupied states and, thus, of the chemical state of the excited atom.

An important limitation in X-ray microscopy is radiation damage. Photo-absorption leads to excitation of electrons and subsequent decay channels that are dominated by the release of low-energy secondary electrons and, thus, the basic processes of radiation damage are very similar to those in electron beam methods $[17,24,79]$. Several studies have investigated radiation damage in X-ray microscopy with respect to resonant and non-resonant excitation, radiation chemistry and fundamental decomposition principles-mainly for soft organic matter [79-92]. All investigations found that X-ray induced chemistry can be quantitatively correlated with the absorbed dose $d$ that is calculated by $[83,87]$ :

$$
\begin{gathered}
d=\frac{F \times t \times E}{\varepsilon \times M} \\
F=I_{0} \times\left[1-e^{-O D}\right] .
\end{gathered}
$$

Within Equation (4) $F$ is the number of absorbed photons per second that is calculated from the number of incident photons $I_{0}$ and the energy-dependent optical density (OD) of the material (Equation (5)). $t$ is the acquisition time per area, $E$ the photon energy in $\mathrm{eV}, \varepsilon$ is the dimensionless detector efficiency, and $M$ is the mass of excited material, typically calculated from excited area and material density. $\varepsilon$ has to be checked regularly, since it is strongly energy dependent and may vary 
over time [21,93]. Note, that this consideration of radiation damage with respect to the absorbed dose is different from the point of view in additive lithography that usually relates the amount of deposited material to the number of required photons [21,22].

In most STXM studies, X-ray induced radiation chemistry is considered to be avoided and, therefore, referred to as "radiation damage". The afore-mentioned dosimetric studies usually aim to define critical doses or at least an estimate of experimental limits that should be respected to obtain reliable microscopic and/or spectroscopic data from the investigated specimen. However, under certain circumstances, radiation induced chemical alteration of materials during X-ray microscopic investigation can be exploited for benefits, such as chemically selective direct-write X-ray lithography with polymer resists [33-37], material selective contrast enhancement for improved microscopic imaging of otherwise intricate specimens [90], or using X-rays as release triggers for polymer based microcontainers with potential applications in drug transport, medical imaging and catalysis [94]. FXBID represents another useful application of X-ray induced radiation chemistry.

\section{Current FXBID Set-Up}

A scheme of FXBID in its present state of development is depicted in Figure 3. The setup has been implemented into the PolLux-STXM at the Swiss Light Source (SLS) [66]. The precursor gas is provided within an environmental gas flow cell that has been initially designed for in-situ studies in the fields of atmosphere chemistry and catalysis [95,96]. The precursor gas flows between two sealed $\mathrm{Si}_{3} \mathrm{~N}_{4}$-membranes with a thickness of $50 \mathrm{~nm}$ each. Such membranes are standard sample supports in STXM. After focusing on one of the two membranes, the substrate area selected for deposition is raster-scanned through the focal spot of the Fresnel zone plate by piezo scanners. The transmitted photons are detected down-stream by a scintillator assisted PMT or an avalanche photodiode (APD) [21].

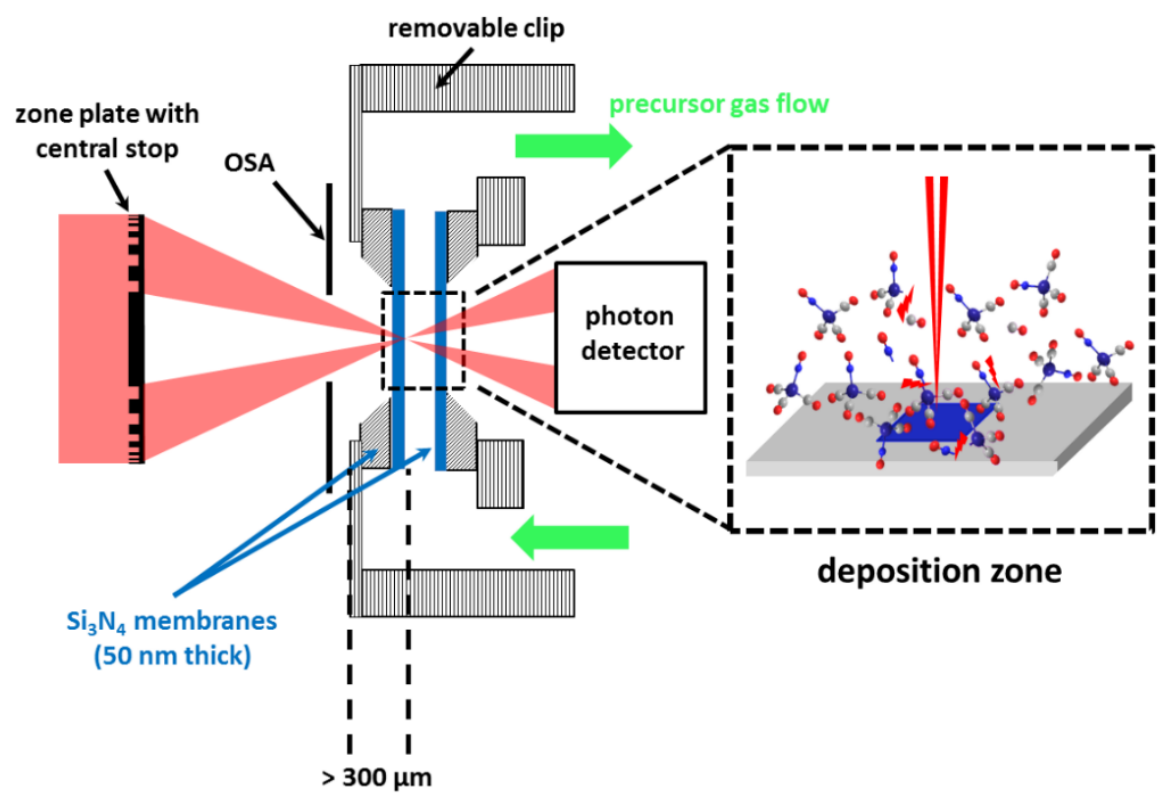

Figure 3. Scheme of the current focused soft X-ray beam induced deposition (FXBID) setup implemented at the PolLux-STXM. The precursor gas is provided within a gas flow cell mainly consisting of two sealed $\mathrm{Si}_{3} \mathrm{~N}_{4}$-membranes. The incident $\mathrm{X}$-ray beam is focused onto one of the two membranes for spatially confined deposition of metallic nanostructures.

The PolLux endstation is usually operated under high vacuum conditions $\left(10^{-6}\right.$ mbar regime) [66]. The precursor gas is supplied towards the gas flow cell in $3 \mathrm{~mm}$ thick tubes. Also, the gas cell itself has to be kept as thin as possible to fit in-between OSA and photon detector. The support plate of the front 
membrane has a thickness of $100 \mu \mathrm{m}$ and the Si frame carrying the membrane is $200 \mu \mathrm{m}$ thick [95]. The membranes should be mounted such that the flat side of the frame is pointing towards the inside of the gas cell. Otherwise the membranes are more prone to breaking when the pressure inside the cell excels the surrounding pressure within the STXM chamber. The membrane frames are glued onto the support with adhesives suitable for vacuum. Therefore, the minimum distance of the deposition zone from the most upstream extension of the gas flow cell towards the optics is currently $300 \mu \mathrm{m}$.

The OSA has to be placed at a position between the Fresnel zone plate and the focal spot that enables blocking of the already divergent higher diffraction order light (Equation (2)), but avoids shadowing of the illumination cone of the first diffraction order [76]. Therefore, all FXBID experiments so far have been performed with Fresnel zone plates with $\Delta r_{N}>25 \mathrm{~nm}$ and still the carbon K-edge (280-320 eV) could not be explored [21,22]. Higher resolving zone plates or photon energies significantly smaller than $\sim 400 \mathrm{eV}$ would lead to a collision of OSA and gas cell at proper focus position. It should also be mentioned that the present setup does not allow for proper measurements of the pressure within the gas cell. The pressure cell is placed outside the PolLux chamber. Due to the small required diameters of the gas cell itself and the supply tubes, a relatively poor pumping cross-section is expected.

\section{What We Have Already Learned About FXBID}

FXBID experiments have been successfully performed with cobalt tricarbonyl nitrosyl $\left(\mathrm{Co}(\mathrm{CO})_{3} \mathrm{NO}\right)[21,22]$, methylcyclopentadienyl manganese tricarbonyl $\left(\mathrm{MeCpMn}(\mathrm{CO})_{3}\right)$ [22], and meanwhile also with iron pentacarbonyl $\left(\mathrm{Fe}(\mathrm{CO})_{5}\right)$. FXBID yields spatially defined metallic nanostructures that can be in-situ characterized by STXM and NEXAFS in terms of shape, growth rate and chemical purity (Figure 4). There is no evidence of significant proximity effects. However, proximity effects for FEBIP on thin $\mathrm{Si}_{3} \mathrm{~N}_{4}$-membranes are also small for low excitation doses due to reduction of the interaction volume $[97,98]$. The amount of deposited material exhibits direct linear dependence with the dwell time and the supplied precursor pressure. The growth rates vary with incident photon energy. It is concluded that the growth rate at different photon energies is influenced by the absorption cross-section of the respective precursor molecule.

Photon energy dependent growth rates have been investigated in detail at the following absorption edges:

- $\mathrm{Co}(\mathrm{CO})_{3} \mathrm{NO}: \mathrm{Co}_{3}$-edge $(\sim 780 \mathrm{eV}), \mathrm{O}$ K-edge $(\sim 530 \mathrm{eV}), \mathrm{N}$ K-edge $(\sim 395 \mathrm{eV})$,

- $\quad \mathrm{Fe}(\mathrm{CO})_{5}: \mathrm{Fe} L_{3}$-edge $(\sim 710 \mathrm{eV}), \mathrm{O}$ K-edge $(\sim 530 \mathrm{eV})$, and

- $\mathrm{MeCpMn}(\mathrm{CO})_{3}: \mathrm{Mn} L_{3}$-edge $(\sim 640 \mathrm{eV})$.

At all absorption edges deposits have been fabricated with incident photon energies below, above and on resonance. Since gas-phase spectra of the precursors could not be recorded at the PolLux STXM, the resonant photon energies had to be estimated based on NEXAFS spectra of previously deposited test structures. This is, however, not necessarily correct, since the respective atoms within the deposits might have significantly different chemical states than within the precursor complexes. Nevertheless, in every case significant enhancement of growth rates up to $40 \%$ is detected at resonant incident photon energies [21,22] (cf. also Section 5).

An overview of FXBID studies on $\mathrm{Co}(\mathrm{CO})_{3} \mathrm{NO}$ is presented in Figure 4. Figure 4a shows an in-situ STXM image of FXBID deposits fabricated with various settings in terms of incident photon energy and dwell time per pixel. After recording of Co $L_{3}$-edge NEXAFS spectra from test deposits, the photon energies had been chosen as follows:

- $\quad 770$ eV: Well below Co $L_{3}$-edge $\rightarrow$ no resonant excitation at the Co center of the precursor,

- $\quad 780 \mathrm{eV}$ : Close to absorption maximum $\rightarrow$ resonant absorption at Co center, and

- 800 eV: Well above Co $L_{3}$-edge $\rightarrow$ declining absorption cross-section, mainly photoelectrons. 


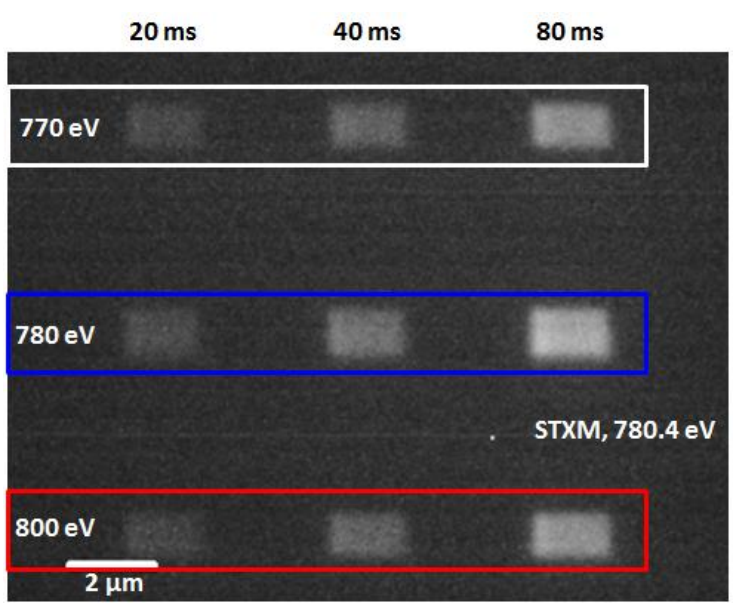

(a)

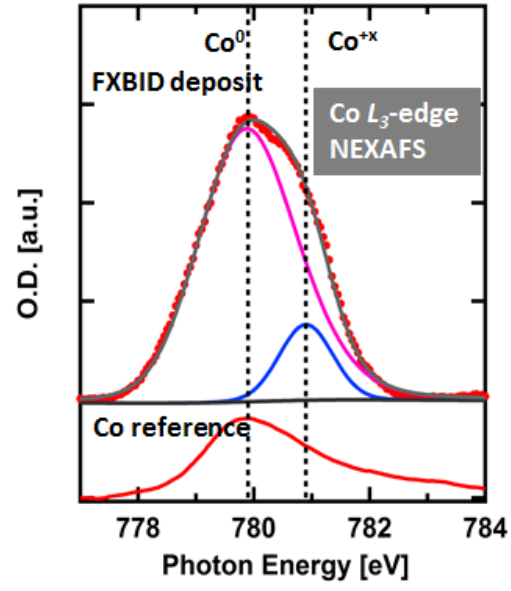

(b)

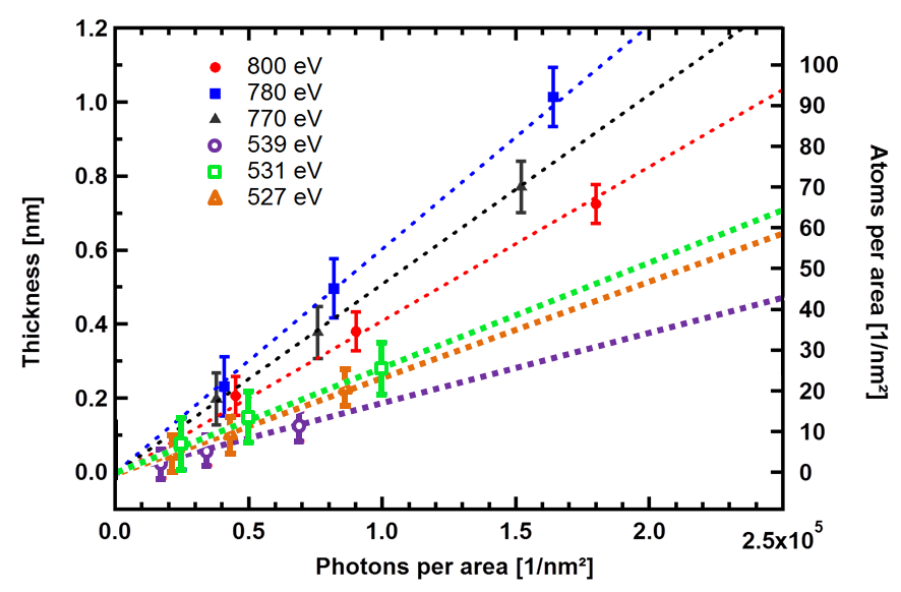

(c)

Figure 4. Exemplary data from FXBID with $\mathrm{Co}(\mathrm{CO})_{3} \mathrm{NO}$ and subsequent characterization. (a) STXM micrograph (optical density) of FXBID nanostructures deposited with three different incident photon energies around the $\mathrm{Co} \mathrm{L}_{3}$-edge (pre-edge, resonant, and post-edge) and varied illumination time per pixel $\left(100 \times 50\right.$ pixel per deposit). (b) Comparison of Co $L_{3}$-edge NEXAFS spectra from an exemplary FXBID deposit with the reference spectrum from a clean Co film. Pink and blue curves represent two individual chemical states and their relative intensities required for fitting of the deposit spectrum. (c) Growth rates of FXBID deposits at various photon energies (normalized to energy dependent variations of the incident photon flux). (a,b) reproduced in revised form from [21] with permission by Royal Society of Chemistry. (c) Reprinted from [47] with permission by Cambridge University Press.

The STXM micrograph in Figure 4a has been normalized on incident flux to depict local optical density. Therefore, the brighter an area appears in this image, the more Co has been deposited at the respective position. The patterning time is mainly determined by the pixel density and the dwell time per pixel, since the motion of the piezo-scanner is negligible for dwell times $>20 \mathrm{~ms}$ ). It is clearly visible that an extension of the dwell time yields more Co, while resonant excitation at $780 \mathrm{eV}$ excels non-resonant excitation below and above the investigated absorption edge. Co $L_{3}$-edge NEXAFS spectra (Figure $4 \mathrm{~b}$ ) of these deposits confirm the presence of Co. Proper fitting of these spectra requires two peaks representing two individual chemical states of Co within the deposits. Comparison with a reference from a clean Co film (prepared by physical vapor deposition) shows that the dominant contribution to the deposit spectrum stems from $\mathrm{Co}^{0}$, while a minor portion is Co in undefined oxidized form $\left(\mathrm{Co}^{+\mathrm{x}}\right)$. 
An inspection of solely $\mathrm{Co}_{2}$-edge NEXAFS spectra would suggest a decent chemical purity of the investigated FXBID deposits from $\mathrm{Co}(\mathrm{CO})_{3} \mathrm{NO}$. However, respective $\mathrm{C}$ and $\mathrm{O} \mathrm{K}$-edge spectra show a high degree of contamination [21]. Especially C K-edge NEXAFS is a good indicator to monitor the purity of FXBID nanostructures. It should be mentioned, however, that due to the smaller focal length at the $\mathrm{C} K$-edge $(\sim 285 \mathrm{eV})$, the respective substrate has to be removed from the present gas cell set-up. Therefore, C NEXAFS is not recorded in-situ. The relatively high carbon content is attributed to a comparably low base pressure within the gas cell resulting in deposition from residual gas and the CO ligands of the precursor molecule. The detected C K-edge NEXAFS spectra are in accordance with spectra from "dead-end"-products of long-time illuminated carbon containing material that has reached a state that cannot be further altered solely by X-ray illumination [89,99]. Due to the relatively high contamination level it was not surprising that XMCD imaging of the respective deposit did not yield any contrast indicating magnetic properties from pure Co or respective pure oxides. The spectroscopic analyses of FXBID deposits from $\mathrm{Fe}(\mathrm{CO})_{5}$ and $\mathrm{MeCpMn}(\mathrm{CO})_{3}$ yielded similar results in terms of contamination levels. A major difference regarding $\mathrm{MeCpMn}(\mathrm{CO})_{3}$ is the lack of $\mathrm{Mn}^{0}$ in $\mathrm{Mn}$ $L_{3}$-edge NEXAFS [22]. Instead, a mixture of various oxidation states from $\mathrm{Mn}^{2+}$ to $\mathrm{Mn}^{4+}$ was detected (Figure 5). Thus, the chemical analysis suggests that a significant improvement of deposit purity is crucial within subsequent steps of the FXBID project.

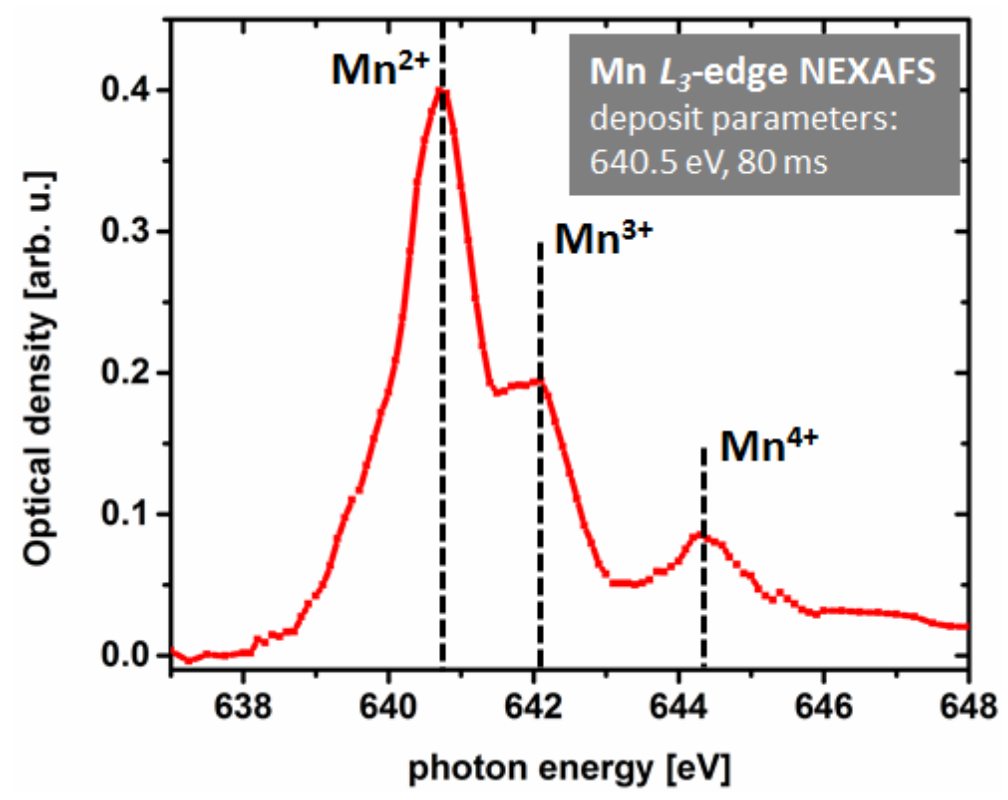

Figure 5. Mn $L_{3}$-edge NEXAFS spectrum of an exemplary FXBID deposit from $\mathrm{MeCpMn}(\mathrm{CO})_{3}$ (on-resonance deposition). According to reference data at least three individual oxidation states from $\mathrm{Mn}^{2+}$ to $\mathrm{Mn}^{4+}$ are detected [22].

Figure 4c provides a comparison of FXBID growth rates from $\mathrm{Co}(\mathrm{CO})_{3} \mathrm{NO}$ at various incident photon energies. Not only resonant and non-resonant excitation are compared, but also excitation around the $\mathrm{Co} \mathrm{L}_{3}$-edge with respective photon energies below, above and on the main resonance of $\mathrm{O}$ K-edge spectra of previous test deposits. Excitation energies at the $\mathrm{N} K$-edge have also been tested [22]. However, the resulting deposition rates were very low. This is attributed to the use of $\mathrm{Si}_{3} \mathrm{~N}_{4}$ membranes that are strongly absorbing at the $\mathrm{N}$ K-edge. Thus, the incident photon flux within the gas cell is significantly reduced. A more detailed evaluation of this issue is intended by using comparable $\mathrm{SiO}_{2}$ membranes in future experiments. Deposition at the $\mathrm{C} K$-edge was not possible with the current set-up due to spatial constraints from decreasing focal length (Equation (2)).

For all applied photon energies we detect a linear dependence of deposition with illumination time. After normalization with respect to energy dependent variations of the incident photon flux (including detector efficiency), we detect that resonant excitation always leads to increased deposition 
rates compared to non-resonant photon energies. The same trend is found for $\mathrm{MeCpMn}(\mathrm{CO})_{3}$ at the $\mathrm{Mn} L_{3}$-edge [22]. When the two depicted absorption edges are compared, we observe that excitation at the $\mathrm{Co}_{3}$-edge is more likely to result in deposition compared to the $\mathrm{O} \mathrm{K}$-edge. A more detailed analysis of this aspect has to take also the different absorption cross-sections at these edges and the higher density of excitable oxygen atoms per volume (the precursor contains $4 \times$ more oxygen than cobalt atoms) into account [22]. The sum of both factors should favor fragmentation at the $\mathrm{O} K$-edge. Therefore, the experimental results suggest an increased probability of precursor splitting when the initial X-ray induced excitation is localized at the metal center of the precursor complex. This hints on variations of the fragmentation process with excitation photon energy, which might be relevant in terms of potential optimizations of the FXBID process. At the present state more detailed insights into the fundamental processes during excitation at various relevant photon energies are required for a more conclusive interpretation of these observations.

Subsequent experiments focused on the application of in-situ cleaning procedures. Within a first test, several Co deposits were fabricated under identical FXBID conditions $(1 \times 0.5 \mu \mathrm{m}, 100 \times$ 50 pixel, $3.0 \times 10^{-5}$ mbar $\mathrm{Co}(\mathrm{CO})_{3} \mathrm{NO}, 100 \mathrm{~ms}$ dwell time per pixel) and subsequently exposed to $1.0 \times 10^{-4}$ mbar $\mathrm{H}_{2} \mathrm{O}$. While $\mathrm{H}_{2} \mathrm{O}$ was constantly provided, some deposits were illuminated again with identical pixel density and dwell time as during the initial fabrication cycle. The excitation photon energy for both cycles was $781 \mathrm{eV}$ (Co $L_{3}$-resonance). Afterwards NEXAFS spectra were recorded for deposits that were illuminated during $\mathrm{H}_{2} \mathrm{O}$ dosing and for those that were not illuminated. $\mathrm{H}_{2} \mathrm{O}$ exposure without $\mathrm{X}$-ray illumination shows no spectroscopic effect with respect to deposits that were not treated with $\mathrm{H}_{2} \mathrm{O}$ at all. Deposits that were exposed to $\mathrm{H}_{2} \mathrm{O}$ and $\mathrm{X}$-rays simultaneously, however, exhibit significant differences in their respective NEXAFS spectra. Exemplary C K-edge NEXAFS spectra are shown in Figure 6. The post-treatment leads to a drop of post-edge optical density. This is a clear indicator for an overall loss of carbonaceous material during the process. Furthermore, a new sharp resonant at $\sim 290 \mathrm{eV}$ appears within the spectrum. Those peaks are a typical fingerprint for the presence of $\mathrm{C}=\mathrm{O}$ bonds and excitations into $\pi^{*} \mathrm{C}=\mathrm{O}$-orbitals [55]. We can conclude that the applied post-treatment procedure induces photo-oxidation of the carbonaceous material within the deposits that is also partially degassing and pumped off. It is not surprising, that the Co NEXAFS spectra, however, also show a significant oxidation of the metallic portion of the respective deposits. Within a subsequent step it must be evaluated whether $\mathrm{H}_{2} \mathrm{O}$ processing can be used to remove carbonaceous material more or less completely. Other reactive gases such as $\mathrm{H}_{2}$ might be investigated aiming on not only clean deposit, but also a higher portion of $\mathrm{Co}^{0}$ in the final product.

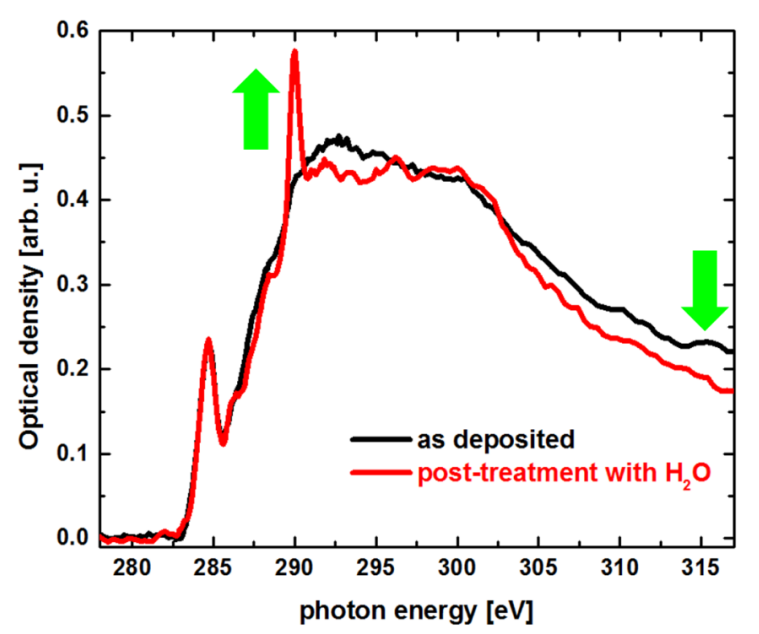

Figure 6. $\mathrm{C}$ K-edge NEXAFS spectra from Co FXBID deposits $\left(\mathrm{Co}(\mathrm{CO})_{3} \mathrm{NO}\right.$ precursor) before (black) and after dosing and photo-induced reaction with $\mathrm{H}_{2} \mathrm{O}$ (red). Green arrows highlight the prominent changes in the spectrum. While a post-edge decrease of optical density indicates an overall removal of carbonaceous material, the rise of a peak at $\sim 290 \mathrm{eV}$ is a sign of oxidation. 
It was also investigated whether FXBID deposits show significant autocatalytic growth. Under the present experimental conditions this effect was very small, more or less negligible. It took several hours of subsequent precursor dosing to observe a noticeable increase of optical densities of previously deposited FXBID structures. On the one hand this is advantageous at the current status of the project, since deposits do not alter significantly during fabrication of further structures and several deposits can be analyzed in parallel after removal of the precursor gas. However, autocatalytic growth is an important mechanism towards clean deposits in FEBIP [1,15,100,101]. We propose that the current gas flow cell does not provide sufficiently clean conditions for proper autocatalytic growth and any catalytic effect is quenched by rapid contamination of deposited metal atoms.

\section{Required Next Steps}

It has been confirmed by previous experiments that deposition rates in FXBID are influenced by the incident photon energy [21,22,47]. However, this effect has to be studied in more detail. Transition metal L-edge spectra exhibit usually very sharp and intense LUMO peaks excelling non-resonant absorption cross-section by several factors $[46,102,103]$. The $X$-ray absorption resonances of the applied precursor molecules should, therefore, be much more dominant compared to the present results of growth rate enhancements of up to $40 \%$ [21,22]. To address this topic, it is necessary to record calibrated gas-phase NEXAFS spectra of the intended precursor molecules at a suitable instrument [104,105] and to correlate those spectra with time-dependent density functional theory (TD-DFT) calculations for proper evaluation of the recorded spectral features [106,107]. Such calculations will for each relevant excitation photon energy yield details on the localization of the respective final state levels within the precursor molecules. Recording mass spectra of the fragmentation products at the same photon energies might yield correlations between final state localization and precursor splitting. Furthermore, incident photon energy dependent secondary electron spectra will be measured, since changes in the energy distribution of the emitted secondary spectra should influence precursor decomposition drastically. Deviations from the resonance energies detected for gas-phase precursor molecules and the photon energies yielding maximum FXBID deposition rates might give insights into chemical states of the precursor molecules when absorbed onto the respective substrate.

In terms of purity of the FXBID deposits it is of course possible to apply ex-situ post-processing techniques that are known from the FEBIP community $[15,19]$. However, it is also intended to evaluate further in-situ cleaning procedures such as co-dosing of reactive gases and in-situ annealing. The latter requires the implementation of heatable $\mathrm{Si}_{3} \mathrm{~N}_{4}$-membranes into the gas flow cell. This can be addressed by deposition of Pt or Au wires onto the membrane resulting in a microstructured resistivity heater [108].

The interactions of the precursor and the X-ray beam with the substrate have to be investigated in detail. While these topics have been addressed in depth by the FEBIP community $[2,3,15,98,109]$, there is still very limited literature about the chemical and physical interactions of metal organic precursors with $\mathrm{Si}_{3} \mathrm{~N}_{4}$-membranes. Furthermore, it is important to understand to which portions secondary electrons from the substrate are contributing to precursor splitting compared to excitation of the precursor molecules themselves. Figure 7 depicts two potential situations. In Figure 7a decomposition from resonant excitation of the precursor molecules is dominant over the constant background from the substrate. This does not necessarily require that the precursor molecules are emitting more secondary electrons than the substrate. It could also means that the resonantly emitted electrons are in sum more destructive towards the precursor. In this case FXBID would exhibit a strong enhancement of deposition rates for resonant energies and tuning of the excitation energy would yield large effects. In Figure $7 \mathrm{~b}$ the constant background from the non-resonantly excited substrate is dominant. In that case, photon energy dependent effects would be close to negligible. However, an excitation photon energy close to the N K-edge should induce enhanced secondary electron emission from the substrate. The respective yields might differ for various substrates and precursors. Without a major change of the present FXBID setup an evaluation of substrate effect could be performed by using $\mathrm{SiO}_{2}$-membranes 
that have similar technical properties as the standard $\mathrm{Si}_{3} \mathrm{~N}_{4}$-membranes. Furthermore, lab-based thermal desorption spectroscopy (TPD) investigations of the intended precursors on such membranes might contribute valuable insights on precursor-substrate interactions by analysis of the respective absorption energies.

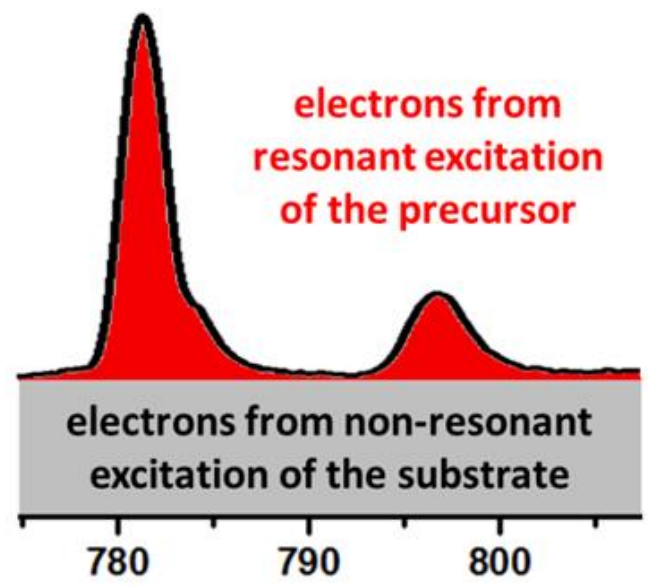

(a)

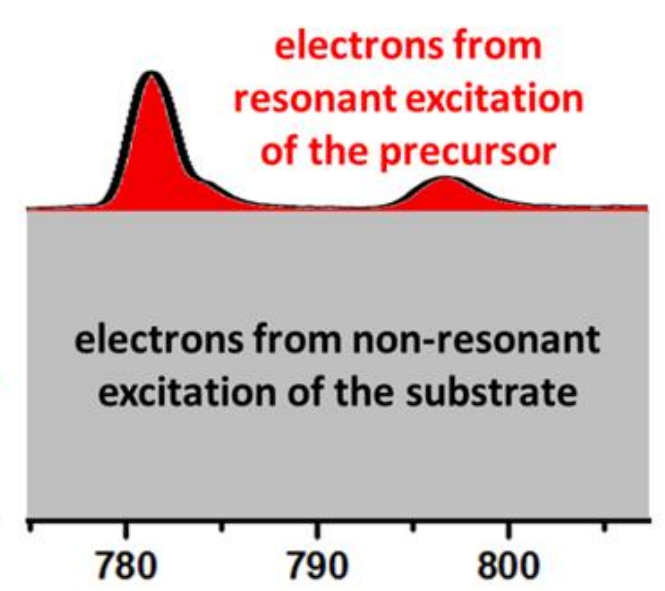

(b)

Figure 7. Scheme on the respective contributions of substrate and precursor excitation to overall precursor splitting. (a) Excitation of precursor molecules is dominant. FXBID growth rate has a strong dependence on excitation photon energy at the respective absorption edge. (b) Excitation of the substrate is dominant. Excitation photon energy has little impact on deposition rate.

In the long term a significant improvement of the chemical purity of the fabricated nanostructures and the successful application of in-situ purification techniques is expected to require a more dedicated setup. The current gas flow cell should be replaced by a two chamber setup with the Fresnel zone plate located in the upstream chamber to be protected from the precursor gas and the substrate in the downstream chamber that can be pumped well into the (U)HV regime. The precursor gas could then be provided by a gas nozzle close to the substrate to achieve a configuration more similar to common FEBIP setups. The two chambers would be connected by a small pinhole along the optical axis that might act as OSA and could even be sealed by a sufficiently transparent membrane window without excessive loss of photon flux. The most sophisticated issue in the design of a two chamber setup is the design of a separator with confined thickness in the area close to the optical axis to allow for a proper alignment of all optical elements and proper focusing of the substrate. In the best case, OSA-to-sample distances $<200 \mu \mathrm{m}$ should be aimed for to enable the use of higher resolving Fresnel zone plates and deposition at the C K-edge. Previous experiments on XRL with STXM have shown that the achievable patterning resolution for that approach is in the range of the minimum spot size of the applied Fresnel zone plate $[36,37]$. In FXBID the mean free path of the occurring secondary electrons is negligible and it is proposed that proximity effects play a minor role. Therefore, the spot size should again be the major limitation for spatial resolution. With the suggested setup improvements, implementation of Fresnel zone plates with $15 \mathrm{~nm}$ spot size should be realistic.

An important step towards complex FXBID nanostructures would be the implementation of 3D deposition. STXM is in general a technique for 2D imaging of thin specimens and the respective instruments are designed for such experiments. Only few real 3D studies on suitable objects have been performed employing either focal stack reconstruction [110,111] or tomography [112-114]—each dealing with various experimental constraints. However, recent developments are using the laminography concept that is similar to tomography, but uses a rotation angle that is not perpendicular to the optical axis and extend this approach towards soft X-ray 3D imaging [115-117]. This method requires a proper 3D scanning of the specimen with retained focus. The hardware activation, controls scripts and reconstruction resources required for laminography imaging can be exploited for controlled 
and automatized 3D FXBID deposition as well as the subsequent 3D spectroscopic imaging of the resulting nanostructures.

\section{Perspectives or: What FXBID Might Be Good For}

The major disadvantage of current FXBID is the necessity of a synchrotron source and a STXM setup which heavily restricts availability and accessibility of the technique. However, on the long term it might be possible to transfer the technique to lab-based X-ray sources and simplified instrumentation. If further investigations reveal a limited effect of incident photon energy on the respective deposition rates, it is not necessary to provide a tunable X-ray source for specified technical applications.

One of the advantages of FXBID is that by tuning of the incident photon energy, the approach provides an adjustable trigger for different precursor splitting rates. Depending on the dimension of this effect, monochromatic focused soft X-rays could be employed for various applications similar to FEBIP, such as 3D nanofabrication, spatially confined substrate functionalization or pattern repair. A potential strength, however, may be photon energy dependent fragmentation of precursor molecules, which has potential to further enhance the in-situ purity of the resulting FXBID deposits. It has been shown that X-ray induced fragmentation of certain relevant precursor molecules exhibits photon energy dependency not only in terms of fragmentation rates, but also fragmentation chemistry, i.e., changing relative intensities of various fragments $[103,118,119]$. Such effects could be exploited to select photon energies for FXBID that result in a high ratio of low mass fragments (in ideal cases only the metal center itself) versus high mass fragments leading to implantation of a large amount of alien atoms from the ligands into the resulting deposits.

An inherent advantage of FXBID over FEBIP/FIBIP is illustrated in Figure 8. Focused X-rays have a significantly higher penetration depth than electrons or ions [78]. Depending on the material density and composition, soft $\mathrm{X}$-rays can penetrate matter up to several $\mu \mathrm{m}$ prior to significant decay. Therefore, FXBID could be useful for the functionalization of porous substrates or buried structures with the only limitation that the precursor gas has to reach the intended deposition zone. Deposition in the depth of (nano)porous substrates is a common task in recent atomic layer deposition (ALD) studies targeting on highly reactive catalysts or absorbing agents with extra-large surfaces [120-126]. FXBID could also be used in terms of a photon assisted ALD process and contribute to increased functionalization rates, deposition from otherwise too stable precursors and spatially confined functionalization.

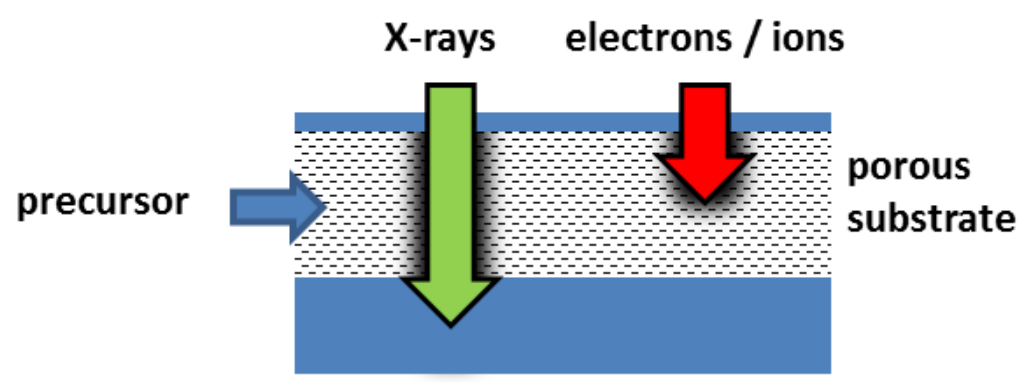

Figure 8. Comparison of penetration depths of X-rays and electrons/ions. In terms of functionalization of porous substrates FXBID allows for depositions zones several $\mu \mathrm{m}$ below the surface of the substrate and might outperform FEBIP/FIBIP.

Taking all aspects into account FXBID has the potential to provide completely new routes for controlled bottom-up fabrication of complex metallic nanostructures and for the functionalization of sufficiently thin 3D substrates targeting a broad field of applications.

Funding: This research received funding by Deutsche Forschungsgemeinschaft (DFG) grant SP 1775/1-1. The PolLux end station received funding by the German Minister für Bildung und Forschung (BMBF) through contracts 05K16WED and 05K19WE2. The author acknowledges travel support to Elettra Sincrotrone by project CALIPSOplus under Grant Agreement 730872 from the EU Framework Programme for Research and Innovation HORIZON 2020. 
Acknowledgments: The author acknowledges the following colleagues for their valuable scientific co-operation within the FXBID project: Rainer H. Fink, Kim Thomann, Benedikt Wolz, Bernd Kreß (Physical Chemistry II, FAU Erlangen-Nuremberg, Germany), Wolfgang Hieringer (Theoretical Chemistry, FAU Erlangen-Nuremberg, Germany), Hubertus Marbach, Fan Tu (formerly FAU, now both at Carl Zeiss SMT GmbH, Roßdorf, Germany), Florian Vollnhals (Innovation Institute for Nanotechnology and Correlative Microscopy (INAM), Forchheim, Germany), Jörg Raabe, Simone Finizio, Sina Mayr, Benjamin Watts, Blagoj Sarafimov (Swiss Light Source, Paul Scherrer Institute, Villigen, Switzerland), Benedikt Rösner (Laboratory for Advanced Photonics, Paul Scherrer Institute, Villigen, Switzerland), Kevin C. Prince, Robert Richter (Elettra Sincrotrone, Trieste, Italy), Sven Barth (Physics Institute, Goethe University Frankfurt, Germany), Matthew Shand (Silson Ltd., Southam, Warwickshire, Great Britain), Torsten Prescher (BCE Special Ceramics GmbH, Mannheim, Germany). The Graduate School Molecular Science (GSMS) at FAU is acknowledged for providing the creative environment in which the FXBID concept was initially developed.

Conflicts of Interest: The author declares no conflicts of interest.

\section{References}

1. Huth, M.; Porrati, F.; Schwalb, C.; Winhold, M.; Sachser, R.; Dukic, M.; Adams, J.; Fantner, G. Focused electron beam induced deposition: A perspective. Beilstein J. Nanotechnol. 2012, 3, 597-619. [CrossRef] [PubMed]

2. Van Dorp, W. Sub-10 nm writing: Focused electron beam-induced deposition in perspective. Appl. Phys. A 2014, 117, 1615-1622. [CrossRef]

3. Marbach, H. Electron beam induced surface activation: A method for the lithographic fabrication of nanostructures via catalytic processes. Appl. Phys. A 2014, 117, 987-995. [CrossRef]

4. Winkler, R.; Schmidt, F.-P.; Haselmann, U.; Fowlkes, J.D.; Lewis, B.B.; Kothleitner, G.; Rack, P.D.; Plank, H. Direct-Write 3D Nanoprinting of Plasmonic Structures. ACS Appl. Mater. Interfaces 2017, 9, 8233-8240. [CrossRef] [PubMed]

5. Kumar, T.P.R.; Unlu, I.; Barth, S.; Ingólfsson, O.; Fairbrother, H.D. Electron induced surface reactions of $\mathrm{HFeCo}_{3}(\mathrm{CO})_{12}$, a bimetallic precursor for focused electron beam induced deposition (FEBID). J. Phys. Chem. C 2018, 122, 2648-2660.

6. Keller, L.; Al Mamoori, M.K.I.; Pieper, J.; Gspan, C.; Stockem, I.; Schröder, C.; Barth, S.; Winkler, R.; Plank, H.; Pohlit, M.; et al. Direct-write of free-form building blocks for artificial magnetic 3D lattices. Sci. Rep. 2018, 8, 6160. [CrossRef]

7. Ahlenhoff, K.; Preischl, C.; Swiderek, P.; Marbach, H. Electron beam-induced surface activation of metal-organic framework HKUST-1: Unraveling the Underlying Chemistry. J. Phys. Chem. C 2018, 122, 26658-26670. [CrossRef]

8. Swiderek, P.; Marbach, H.; Hagen, C.W. Chemistry for electron-induced nanofabrication. Beilstein J. Nanotechnol. 2018, 9, 1317-1320. [CrossRef]

9. Höflich, K.; Jurczyk, J.M.; Madajska, K.; Götz, M.; Berger, L.; Guerra-Nuñez, C.; Haverkamp, C.; Szymanska, I.; Utke, I. Towards the third dimension in direct electron beam writing of silver. Beilstein J. Nanotechnol. 2018, 9, 842-849. [CrossRef]

10. Huth, M.; Porrati, F.; Dobrovolskiy, O.V. Focused electron beam induced deposition meets materials science. Microelectron. Eng. 2018, 185-186, 9-28. [CrossRef]

11. Di Prima, G.; Sachser, R.; Trompenaars, P.; Mulders, H.; Huth, M. Direct-write single electron transistors by focused electron beam induced deposition. Nano Futures 2019, 3, 025001. [CrossRef]

12. Pablo-Navarro, J.; Sangiao, S.; Magén, C.; De Teresa, J.M. Diameter modulation of 3D nanostructures in focused electron beam induced deposition using local electric fields and beam defocus. Nanotechnology 2019, 30, 505302. [CrossRef] [PubMed]

13. Córdoba, R.; Urús, P.; Strohauer, S.; Torres, T.E.; De Teresa, J.M. Ultra-fast direct growth of metallic microand nano-structures by focused ion beam irradiation. Sci. Rep. 2019, 9, 14076. [CrossRef] [PubMed]

14. Winkler, R.; Fowlkes, J.D.; Rack, P.D.; Plank, H. 3D nanoprinting via focused electron beams. J. Appl. Phys. 2019, 125, 210901. [CrossRef]

15. Utke, I.; Hoffmann, P.; Melngailis, J. Gas-assisted focused electron beam and ion beam processing and fabrication. J. Vac. Sci. Technol. B 2008, 26, 1197-1276. [CrossRef]

16. Arumainayagam, C.R.; Lee, H.-L.; Nelson, R.B.; Haines, D.R.; Gunawardane, R.P. Low-energy electron-induced reactions in condensed matter. Surf. Sci. Rep. 2010, 65, 1-44. [CrossRef] 
17. Thorman, R.M.; Kumar TP, R.; Fairbrother, H.D.; Ingólfsson, O. The role of low-energy electrons in focused electron beam induced deposition: Four case studies of representative precursors. Beilstein J. Nanotechnol. 2015, 6, 1904-1926. [CrossRef]

18. Kumar TP, R.; Barth, S.; Bjornsson, R.; Ingólfsson, O. Structure and energetics in dissociative electron attachment to $\mathrm{HFeCo}_{3}(\mathrm{CO})_{12}$. Eur. Phys. J. D 2016, 70, 163.

19. Botman, A.; Mulders, J.; Hagen, C. Creating pure nanostructures from electron-beam-induced deposition using purification techniques: A technology perspective. Nanotechnology 2009, 20, 372001. [CrossRef]

20. Shawrav, M.M.; Taus, P.; Wanzenboeck, H.D.; Schinnerl, M.; Stöger-Pollach, M.; Schwarz, S.; Steiger-Thirsfeld, A.; Bertagnolli, E. Highly conductive and pure gold nanostructures grown by electron beam induced deposition. Sci. Rep. 2016, 6, 34003. [CrossRef]

21. Späth, A.; Tu, F.; Vollnhals, F.; Drost, M.; Krick Calderón, S.; Watts, B.; Fink, R.H.; Marbach, H. Additive fabrication of nanostructures with focused soft X-rays. RSC Adv. 2016, 6, 98344-98349. [CrossRef]

22. Tu, F.; Späth, A.; Drost, M.; Vollnhals, F.; Krick Calderón, S.; Fink, R.H.; Marbach, H. Exploring the fabrication of Co and Mn nanostructures with focused soft X-ray beam induced deposition. J. Vac. Sci. Technol. B 2017, 35, 031601. [CrossRef]

23. Sayre, D.; Kirz, J.; Feder, R.; Kim, D.M.; Spiller, E. Transmission microscopy of unmodified biological materials: Comparative radiation dosages with electrons and ultrasoft X-ray photons. Ultramicroscopy 1977, 2, 337-349. [CrossRef]

24. Cazaux, J. A physical approach to the radiation damage mechanisms induced by X-rays in X-ray microscopy and related techniques. J. Microsc. 1997, 188, 106-124. [CrossRef]

25. Cazaux, J. Electron- and X-ray-induced electron emissions from insulators. Polym. Int. 2001, 50, 748-755. [CrossRef]

26. Spears, D.L.; Smith, H.I. High-resolution pattern replication using soft x-rays. Electron. Lett. 1972, 8, $102-104$. [CrossRef]

27. Becker, E.W.; Ehrfeld, W.; Hagmann, P.; Maner, A.; Münchmeyer, D. Fabrication of microstructures with high aspect ratios and great structural heights by synchrotron radiation lithography, galvanoforming, and plastic moulding (LIGA process). Microelectron. Eng. 1986, 4, 35-56. [CrossRef]

28. Ehrfeld, W.; Lehr, H. Deep X-ray lithography for the production of three-dimensional microstructures from metals, polymers and ceramics. Rad. Phys. Chem. 1995, 45, 349-365. [CrossRef]

29. Mojarad, N.; Gobrecht, J.; Ekinci, Y. Interference lithography at EUV and soft X-ray wavelengths: Principles, methods, and applications. Microelectron. Eng. 2015, 143, 55-63. [CrossRef]

30. Maldonado, J.R.; Peckerar, M. X-ray lithography: Some history, current status and future prospects. Microelectron. Eng. 2016, 161, 87-93. [CrossRef]

31. Achenbach, S.; Wells, G.; Jacobs, M.; Moazed, B.; Iyer, S.; Hanson, J. Polymer-based X-ray masks patterned by direct laser writing. Rev. Sci. Instrum. 2018, 89, 115001. [CrossRef] [PubMed]

32. Park, K.; Kim, K.; Lee, S.C.; Lim, G.; Kim, J.H. Fabrication of polymer microstructures of various angles via synchrotron X-ray lithography using simple dimensional transformation. Materials 2018, 11, 1460. [CrossRef] [PubMed]

33. Wang, J.; Stöver, H.D.H.; Hitchcock, A.P. Chemically selective soft X-ray direct-write patterning of multilayer polymer films. J. Phys. Chem. C 2007, 111, 16330-16338. [CrossRef]

34. Wang, J.; Stöver, H.D.H.; Hitchcock, A.P.; Tyliszczak, T. Chemically selective soft X-ray patterning of polymers. J. Synchrotron Radiat. 2007, 14, 181-190. [CrossRef]

35. Leontowich, A.F.G.; Hitchcock, A.P. Zone plate focused soft X-ray lithography. Appl. Phys. A 2011, $103,1-11$. [CrossRef]

36. Leontowich, A.F.G.; Hitchcock, A.P. Zone plate focused soft X-ray lithography for fabrication of nanofluidic devices. Proc. SPIE 2012, 8323, 83231D.

37. Leontowich, A.F.G.; Hitchcock, A.P.; Watts, B.; Raabe, J. Sub-25 nm direct write (maskless) X-ray nanolithography. Microelectron. Eng. 2013, 108, 5-7. [CrossRef]

38. Zanoni, R.; Piancastelli, M.N.; McKinley, J.; Margaritondo, G. Synchrotron radiation induced metal deposition on semiconductors: $\mathrm{Mo}(\mathrm{CO})_{6}$ on $\mathrm{Si}(111)$. Appl. Phys. Lett. 1989, 55, 1020-1022. [CrossRef]

39. Mancini, D.C.; Varma, S.; Simons, J.K.; Rosenberg, R.A.; Dowben, P.A. Synchrotron radiation induced chemical vapor deposition of thin films from metal hexacarbonyls. J. Vac. Sci. Technol. B 1990, 8, 1804-1807. [CrossRef] 
40. Takahashi, J.; Utsumi, Y.; Akazawa, H.; Kawashima, I.; Urisu, T. Synchrotron radiation excited Si epitaxial growth using disilane gas source molecular beam system. Appl. Phys. Lett. 1991, 58, 2776-2778. [CrossRef]

41. Ogata, T.; Gheyas, S.I.; Ogawa, H.; Nishio, M. Low-temperature deposition of II-VI compound semiconductors by synchrotron radiation using metalorganic sources. Thin Solid Films 1995, 266, 168-172. [CrossRef]

42. Väterlein, P.; Weiss, M.; Wüstenhagen, V.; Umbach, E. Mask-less writing of microstructures with the PISAM. Appl. Surf. Sci. 1993, 70-71, 278-282. [CrossRef]

43. Väterlein, P.; Wüstenhagen, V.; Umbach, E. Direct writing of Mo microstructures using high brilliance synchrotron radiation. Appl. Phys. Lett. 1995, 66, 2200-2202. [CrossRef]

44. Rösner, B.; Koch, F.; Döring, F.; Bosgra, J.; Guzenko, V.A.; Kirk, E.; Meyer, M.; Loroña Ornelas, J.; Fink, R.H.; Stanescu, S.; et al. Exploiting atomic layer deposition for fabricating sub-10 $\mathrm{nm}$ X-ray lenses. Microelectron. Eng. 2018, 191, 91-96. [CrossRef]

45. Rösner, B.; Koch, F.; Döring, F.; Guzenko, V.A.; Meyer, M.; Loroña Ornelas, J.; Späth, A.; Fink, R.H.; Stanescu, S.; Swaraj, S.; et al. $7 \mathrm{~nm}$ Spatial Resolution in Soft X-ray Microscopy. Microsc. Microanal. 2018, 24, $270-271$. [CrossRef]

46. Vollnhals, F.; Drost, M.; Tu, F.; Carrasco, E.; Späth, A.; Steinrück, H.-P.; Fink, R.H.; Marbach, H. Electron Beam Induced Decomposition and Autocatalytic Growth of $\mathrm{Co}(\mathrm{CO})_{3} \mathrm{NO}$. Beilstein J. Nanotechnol. 2014, 5, 1175-1185. [CrossRef]

47. Späth, A.; Vollnhals, F.; Tu, F.; Prince, K.C.; Richter, R.; Raabe, J.; Marbach, H.; Fink, R.H. Focused soft X-ray beam induced deposition: Recent advances to a novel approach for fabrication of metallic nanostructures. Microsc. Microanal. 2018, 24, 114-115. [CrossRef]

48. Tu, F.; Drost, M.; Vollnhals, F.; Späth, A.; Carrasco, E.; Fink, R.H.; Marbach, H. On the magnetic properties of iron nanostructures fabricated via focused electron beam induced deposition and autocatalytic growth processes. Nanotechnology 2016, 27, 355302. [CrossRef]

49. Kirz, J. Phase zone plates for x rays and the extreme uv. J. Opt. Soc. Am. 1974, 64, 301-309. [CrossRef]

50. Niemann, B.; Rudolph, D.; Schmahl, G. Soft X-ray imaging zone plates with large zone numbers for microscopic and spectroscopic applications. Opt. Commun. 1974, 12, 160-163. [CrossRef]

51. Simpson, M.J.; Michette, A.G. Imaging properties of modified Fresnel zone plates. Opt. Acta 1984, 31, 403-413. [CrossRef]

52. Kirz, J.; Rarback, H. Soft x-ray microscopes. Rev. Sci. Instrum. 1985, 56, 1-13. [CrossRef]

53. Kirz, J.; Sayre, D.; Schmahl, G. Soft-X-ray Microscopes. Phys. Today 1985, 38, 22-33. [CrossRef]

54. Kirz, J.; Jacobsen, C.; Howells, M. Soft X-ray microscopes and their biological applications. Q. Rev. Biophys. 1995, 28, 33-130. [CrossRef] [PubMed]

55. Ade, H.; Hitchcock, A.P. NEXAFS microscopy and resonant scattering: Composition and orientation probed in real and reciprocal space. Polymer 2008, 49, 643-675. [CrossRef]

56. Graf-Zeiler, B.; Fink, R.-H.; Tzvetkov, G. In Situ Synchrotron Radiation X-ray Microspectroscopy of Polymer Microcontainers. Chem. Phys. Chem. 2011, 12, 3503-3509. [CrossRef]

57. Guttmann, P.; Bittencourt, C. Overview of nanoscale NEXAFS performed with soft X-ray microscopes. Beilstein J. Nanotechnol. 2015, 6, 595-604. [CrossRef]

58. Fischer, P.; Ohldag, H. X-rays and magnetism. Rep. Prog. Phys. 2015, 78, 094501. [CrossRef]

59. Hitchcock, A.P. Soft X-ray spectromicroscopy and ptychography. J. Electron Spectrosc. Relat. Phenom. 2015, 200, 49-63. [CrossRef]

60. Baumgartner, M.; Garello, K.; Mendil, J.; Avci, C.O.; Grimaldi, E.; Murer, C.; Feng, J.; Gabureac, M.; Stamm, C.; Acremann, Y.; et al. Spatially and time-resolved magnetization dynamics driven by spin-orbit torques. Nat. Nanotechnol. 2017, 12, 980-986. [CrossRef]

61. Stuckey, J.W.; Yang, J.; Sparks, D.L. Advances in scanning transmission X-ray microscopy for elucidating soil biogeochemical processes at the submicron scale. J. Environ. Qual. 2017, 46, 1166-1174. [CrossRef] [PubMed]

62. Wu, Q.; Soppa, K.; Scherrer, N.; Watts, B.; Yokosawa, T.; Bernard, L.; Araki, T.; Döbeli, M.; Meyer, M.; Spiecker, E.; et al. Investigation of the foil structure and corrosion mechanisms of modern Zwischgold using advanced analysis techniques. J. Cult. Herit. 2018, 31, 122-132. [CrossRef]

63. Nittler, L.R.; Stroud, R.M.; Trigo-Rodríguez, J.M.; De Gregorio, B.T.; Alexander, C.M.; Davidson, J.; Moyano-Cambero, C.E.; Tanbakouei, S. A cometary building block in a primitive asteroidal meteorite. Nat. Astron. 2019, 3, 659-666. [CrossRef] 
64. Finizio, S.; Zeissler, K.; Wintz, S.; Mayr, S.; Weßels, T.; Huxtable, A.J.; Burnell, G.; Marrows, C.H.; Raabe, J. Deterministic Field-Free Skyrmion Nucleation at a Nanoengineered Injector Device. Nano Lett. 2019, 19, 7246-7255. [CrossRef]

65. Kilcoyne, A.L.D.; Tyliszczak, T.; Steele, W.F.; Fakra, S.; Hitchcock, P.; Franck, K.; Anderson, E.; Harteneck, B.; Rightor, E.G.; Mitchell, G.E.; et al. Interferometer-controlled scanning transmission X-ray microscopes at the Advanced Light Source. J. Synchrotron Radiat. 2003, 10, 125-136. [CrossRef]

66. Raabe, J.; Tzvetkov, G.; Flechsig, U.; Böge, M.; Jaggi, A.; Sarafimov, B.; Vernooij, M.G.C.; Huthwelker, T.; Ade, H.; Kilcoyne, D.; et al. PolLux: A new facility for soft X-ray spectromicroscopy at the Swiss Light Source. Rev. Sci. Instrum. 2008, 79, 113704. [CrossRef]

67. Maiden, A.M.; Morrison, G.R.; Kaulich, B.; Gianoncelli, A.; Rodenburg, J.M. Soft X-ray spectromicroscopy using ptychography with randomly phased illumination. Nat. Commun. 2013, 4, 1669. [CrossRef]

68. Shapiro, D.A.; Yu, Y.-S.; Tyliszczak, T.; Cabana, J.; Celestre, R.; Chao, W.; Kaznatcheev, K.; Kilcoyne, A.L.D.; Maia, F.; Marchesini, S.; et al. Chemical composition mapping with nanometre resolution by soft X-ray microscopy. Nat. Photon. 2014, 8, 765-769. [CrossRef]

69. Shin, H.-J.; Kim, N.; Kim, H.-S.; Lee, W.-W.; Lee, C.-S.; Kim, B. A scanning transmission X-ray microscope at the Pohang Light Source. J. Synchrotron Rad. 2018, 25, 878-884. [CrossRef]

70. Hub, C.; Wenzel, S.; Raabe, J.; Ade, H.; Fink, R.H. Surface sensitivity in scanning transmission X-ray microspectroscopy using secondary electron detection. Rev. Sci. Instrum. 2010, 81, 033704. [CrossRef]

71. Behyan, S.; Haines, B.; Karunakaran, C.; Wang, J.; Obst, M.; Tyliszczak, T.; Urquhart, S.G. Surface detection in a STXM microscope. AIP Conf. Proc. 2011, 1365, 184-187.

72. Watts, B.; Ade, H. NEXAFS imaging of synthetic organic materials. Mater. Today 2012, 15, 148-157. [CrossRef]

73. Gianoncelli, A.; Kaulich, B.; Alberti, R.; Klatka, T.; Longoni, A.; de Marco, A.; Marcello, A.; Kiskinova, M. Simultaneous soft X-ray transmission and emission microscopy. Nucl. Instrum. Meth. A 2009, 608, 195-198. [CrossRef]

74. Gianoncelli, A.; Rizzardi, C.; Salomon, D.; Canzonieri, V.; Pascolo, L. Nano-imaging of environmental dust in human lung tissue by soft and hard X-ray fluorescence microscopy. Spectrochim. Acta B 2018, 147, 71-78. [CrossRef]

75. Lühl, L.; Andrianov, K.; Dierks, H.; Haidl, A.; Dehlinger, A.; Heine, M.; Heeren, J.; Nisius, T.; Wilhein, T.; Kanngießer, B. Scanning transmission X-ray microscopy with efficient X-ray fluorescence detection (STXM-XRF) for biomedical applications in the soft and tender energy range. J. Synchrotron Rad. 2019, 26, 430-438. [CrossRef]

76. Attwood, D. Soft X-ray Microscopy with Diffractive Optics. In Soft X-rays and Extreme Ultraviolett Radiation, 1st ed.; Attwood, D., Ed.; Cambridge University Press: Cambridge, UK, 1999; pp. 337-394.

77. Chao, W.; Kim, J.; Rekawa, S.; Fischer, P.; Anderson, E.H. Demonstration of $12 \mathrm{~nm}$ resolution fresnel zone plate lens based soft X-ray microscopy. Opt. Express 2009, 17, 112352. [CrossRef]

78. Henke, B.L.; Gullikson, E.M.; Davis, J.C. X-ray interactions: Photoabsorption, scattering, transmission, and reflection at $\mathrm{E}=50-30,000 \mathrm{eV}, \mathrm{Z}=1-92$. At. Data Nucl. Data Tables 1993, 54, 181-342. [CrossRef]

79. Leontowich, A.F.G.; Hitchcock, A.P.; Egerton, R.F. Radiation damage yields across the carbon 1s excitation edge. J. Electron Spectrosc. Relat. Phenom. 2016, 206, 58-64. [CrossRef]

80. Rightor, E.G.; Hitchcock, A.P.; Ade, H.; Leapman, R.D.; Urquhart, S.G.; Smith, A.P.; Mitchell, G.; Fischer, D.; Shin, H.J.; Warwick, T. Spectromicroscopy of poly(ethylene terephthalate): Comparison of spectra and radiation damage rates in X-ray absorption and electron energy loss. J. Phys. Chem. B 1997, 101, 1950-1960. [CrossRef]

81. Coffey, T.; Urquhart, S.G.; Ade, H. Characterization of the effects of soft X-ray irradiation on polymers. J. Electron Spectrosc. Relat. Phenom. 2002, 122, 65-78. [CrossRef]

82. Beetz, T.; Jacobsen, C. Soft X-ray radiation-damage studies in PMMA using a cryo-STXM. J. Synchrotron Radiat. 2003, 10, 280-283. [CrossRef] [PubMed]

83. Wang, J.; Morin, C.; Li, L.; Hitchcock, A.P.; Scholl, A.; Doran, A. Radiation damage in soft X-ray microscopy. J. Electron Spectrosc. Relat. Phenom. 2009, 170, 25-36. [CrossRef]

84. Braun, A.; Kubatova, A.; Wirick, S.; Mun, S.B. Radiation damage from EELS and NEXAFS in diesel soot and diesel soot extracts. J. Electron Spectrosc. Relat. Phenom. 2009, 170, 42-48. [CrossRef] 
85. Meents, A.; Gutmann, S.; Wagner, A.; Schulze-Briese, C. Origin and temperature dependence of radiation damage in biological samples at cryogenic temperatures. Proc. Natl. Acad. Sci. USA 2010, 107, 1094-1099. [CrossRef] [PubMed]

86. Schmidt, N.; Scheurer, A.; Sperner, S.; Fink, R.H. Microspectroscopic analysis of the X-ray-induced photoreduction in Fe- and Mn-containing SMMs. Z. Naturforsch. 2010, 65b, 390-398. [CrossRef]

87. Leontowich, A.F.G.; Hitchcock, A.P.; Tyliszczak, T.; Weigand, M.; Wang, J.; Karunakaran, C. Accurate dosimetry in scanning transmission X-ray microscopes via the cross-linking threshold dose of poly(methyl methacrylate). J. Synchrotron Radiat. 2012, 19, 976-987. [CrossRef]

88. Leontowich, A.F.G. Utility of the $\mathrm{G}$ value and the critical dose to soft $\mathrm{X}$-ray radiation damage of polyacrylonitrile. Rad. Phys. Chem. 2013, 90, 87-91. [CrossRef]

89. Tzvetkov, G.; Späth, A.; Fink, R.H. Soft X-ray induced damage in PVA-based membranes in water environment monitored by X-ray absorption spectroscopy. Rad. Phys. Chem. 2014, 103, 84-88. [CrossRef]

90. Späth, A.; Watts, B.; Wasserthal, L.T.; Fink, R.H. Quantitative study of contrast enhancement in soft X-ray micrographs of insect eyes by tissue selective mass loss. J. Synchrotron Rad. 2014, 21, 1153-1159. [CrossRef]

91. Gianoncelli, A.; Vaccari, L.; Kourousias, G.; Cassese, D.; Bedolla, D.E.; Kenig, S.; Storici, P.; Lazzarino, M.; Kiskinova, M. Soft X-ray microscopy radiation damage on fixed cells investigated with synchrotron radiation FTIR microscopy. Sci. Rep. 2015, 5, 10250. [CrossRef]

92. Martens, I.; Melo, L.G.A.; Wilkinson, D.P.; Bizzotto, D.; Hitchcock, A.P. Characterization of X-ray damage to perfluorosulfonic acid using correlative microscopy. J. Phys. Chem. C 2019, 123, 16023-16033. [CrossRef]

93. Fakra, S.; Kilcoyne, A.L.D.; Tyliszczak, T. Scintillator detectors for scanning transmission X-ray microscopes at the advanced light source. AIP Conf. Proc. 2004, 705, 973-976.

94. Späth, A.; Minami, H.; Suzuki, T.; Fink, R.H. Morphology changes of ionic liquid encapsulating polymer microcontainers upon X-ray irradiation. RSC Adv. 2014, 4, 3272-3277. [CrossRef]

95. Huthwelker, T.; Zelenay, V.; Birrer, M.; Krepelova, A.; Raabe, J.; Tzvetkov, G.; Vernooij, M.G.C.; Ammann, M. An in situ cell to study phase transitions in individual aerosol particles on a substrate using scanning transmission x-ray microspectroscopy. Rev. Sci. Instrum. 2010, 81, 113706. [CrossRef]

96. Alpert, P.A.; Corral Aroyo, P.; Dou, J.; Krieger, U.K.; Steimer, S.S.; Förster, J.-D.; Ditas, F.; Pöhlker, C.; Rossignol, S.; Passananti, M.; et al. Visualizing reaction and diffusion in xanthan gum aerosol particles exposed to ozone. Phys. Chem. Chem. Phys. 2019, 21, 20613-20627. [CrossRef]

97. Walz, M.-M.; Vollnhals, F.; Rietzler, F.; Schirmer, M.; Steinrück, H.-P.; Marbach, H. Investigation of proximity effects in electron microscopy and lithography. Appl. Phys. Lett. 2012, 100, 053118. [CrossRef]

98. Walz, M.-M.; Vollnhals, F.; Rietzler, F.; Schirmer, M.; Kunzmann, A.; Steinrück, H.-P.; Marbach, H. Thin membranes versus bulk substrates: Investigation of proximity effects in focused electron beam-induced processing. J. Phys. D Appl. Phys. 2012, 45, 225306. [CrossRef]

99. Leontowich, A.F.G.; Hitchcock, A. Secondary electron deposition mechanism of carbon contamination. J. Vac. Sci. Technol. B 2012, 30, 030601. [CrossRef]

100. Drost, M.; Tu, F.; Vollnhals, F.; Szenti, I.; Kiss, J.; Marbach, H. On the Principles of Tweaking nanostructure fabrication via focused electron beam induced processing combined with catalytic growth processes. Small Methods 2017, 1, 1700095. [CrossRef]

101. Drost, M.; Tu, F.; Berger, L.; Preischl, C.; Zhou, W.; Gliemann, H.; Wöll, C.; Marbach, H. Surface-anchored metal-organic frameworks as versatile resists for gas-assisted e-beam lithography: Fabrication of sub-10 nanometer structures. ACS Nano 2018, 12, 3825-3835. [CrossRef]

102. Moreau-Luchaire, C.; Moutafis, C.; Reyren, N.; Sampaio, J.; Vaz, C.A.F.; Van Horne, N.; Bouzehouane, K.; Garcia, K.; Deranlot, C.; Warnicke, P.; et al. Additive interfacial chiral interaction in multilayers for stabilization of small individual skyrmions at room temperature. Nat. Nanotechnol. 2015, 11, 444-448. [CrossRef] [PubMed]

103. Godehusen, K.; Richter, T.; Zimmermann, P.; Wernet, P. Iron L-Edge Absorption Spectroscopy of Iron Pentacarbonyl and Ferrocene in the Gas Phase. J. Phys. Chem. A 2017, 121, 66-72. [CrossRef] [PubMed]

104. Blyth, R.R.; Delaunay, R.; Zitnik, M.; Krempasky, J.; Krempaska, R.; Slezak, J.; Prince, K.C.; Richter, R.; Vondracek, M.; Camilloni, R.; et al. The high-resolution gas phase photoemission beamline, Elettra. J. Electron Spectrosc. Relat. Phenom. 1999, 101-103, 959-964. [CrossRef] 
105. Carlotto, S.; Finetti, P.; de Simone, M.; Coreno, M.; Casella, G.; Sambi, M.; Casarin, M. Comparative experimental and theoretical study of the $\mathrm{Fe}_{2,3}$-edges $\mathrm{X}$-ray absorption spectroscopy in three highly popular, low-spin organoiron complexes: $\left[\mathrm{Fe}(\mathrm{CO})_{5}\right],\left[\left(\eta^{5}-\mathrm{C}_{5} \mathrm{H}_{5}\right) \mathrm{Fe}(\mathrm{CO})(\mu-\mathrm{CO})\right]_{2}$, and $\left[\left(\eta^{5}-\mathrm{C}_{5} \mathrm{H}_{5}\right)_{2} \mathrm{Fe}\right]$. Inorg. Chem. 2019, 58, 5844-5857. [CrossRef]

106. Schmidt, N.; Fink, R.; Hieringer, W. Assignment of near-edge x-ray absorption fine structure spectra of metalloporphyrins by means of time-dependent density-functional calculations. J. Chem. Phys. 2010, 133, 054703. [CrossRef] [PubMed]

107. Atkins, A.J.; Jacob, D.R.; Bauer, M. Probing the electronic structure of substituted ferrocenes with high-resolution XANES spectroscopy. Chem. Eur. J. 2012, 18, 7021-7025. [CrossRef]

108. Baldasseroni, C.; Queen, D.R.; Cooke, D.W.; Maize, K.; Shakouri, A.; Hellman, F. Heat transfer simulation and thermal measurements of microfabricated x-ray transparent heater stages. Rev. Sci. Instrum. 2011, 82, 093904. [CrossRef]

109. Toth, M.; Lobo, C.; Friedli, V.; Szkudlarek, A.; Utke, I. Continuum models of focused electron beam induced processing. Beilstein J. Nanotechnol. 2015, 6, 1518-1540. [CrossRef]

110. Späth, A.; Schöll, S.; Riess, C.; Schmidtel, D.; Paradossi, G.; Raabe, J.; Hornegger, J.; Fink, R.H. STXM goes 3D: Digital reconstruction of focal stacks as novel approach towards confocal soft X-ray microscopy. Ultramicroscopy 2014, 144, 19-25. [CrossRef]

111. Ma, L.; Zhang, X.; Xu, Z.; Späth, A.; Xing, Z.; Sun, T.; Tai, R. Three-dimensional focal stack imaging in scanning transmission $X$-ray microscopy with an improved reconstruction algorithm. Opt. Express 2019, 27, 7787-7802. [CrossRef]

112. Johansson, G.A.; Tyliszczak, T.; Mitchell, G.E.; Keefe, M.H.; Hitchcock, A.P. Three-dimensional chemical mapping by scanning transmission X-ray spectromicroscopy. J. Synchrotron Rad. 2007, 14, 395-402. [CrossRef]

113. Hitchcock, A.P.; Johansson, G.A.; Mitchell, G.E.; Keefe, M.H.; Tyliszczak, T. 3-d chemical imaging using angle-scan nanotomography in a soft X-ray scanning transmission X-ray microscope. Appl. Phys. A 2008, 92, 447-452. [CrossRef]

114. Wang, J.; Hitchcock, A.P.; Karunakaran, C.; Prange, A.; Franz, B.; Harkness, T.; Lu, Y.; Obst, M.; Hormes, J. 3D chemical and elemental imaging by STXM spectrotomography. AIP Conf. Proc. 2011, 1365, 215-218.

115. Gondrom, S.; Zhou, J.; Maisl, M.; Reiter, H.; Kröning, M.; Arnold, W. X-ray computed laminography: An approach of computed tomography for applications with limited access. Nucl. Eng. Des. 1999, 190, 141-147. [CrossRef]

116. Holler, M.; Odstrcil, M.; Guizar-Sicairos, M.; Lebugle, M.; Müller, E.; Finizio, S.; Tinti, G.; David, C.; Zusman, J.; Unglaub, W.; et al. Three-dimensional imaging of integrated circuits with macro- to nanoscale zoom. Nat. Electron. 2019, 2, 464-470. [CrossRef]

117. Witte, K.; Späth, A.; Finizio, S.; Donelly, C.; Watts, B.; Sarafimov, B.; Odstrcil, M.; Guizar-Sicairos, M.; Holler, M.; Fink, R.H.; et al. From 2D STXM to 3D imaging: Soft X-ray laminography of thin specimens. under review.

118. Schalk, O.; Josefsson, I.; Richter, R.; Prince, K.C.; Odelius, M.; Mucke, M. Ionization and photofragmentation of $\mathrm{Ru}_{3}(\mathrm{CO})_{12}$ and $\mathrm{Os}_{3}(\mathrm{CO})_{12}$. J. Chem. Phys. 2015, 143, 154305. [CrossRef]

119. Schalk, O.; Josefsson, I.; Geng, T.; Richter, R.; Sa'adeh, H.; Thomas, R.D.; Mucke, M. Dissociation kinetics of excited ions: PEPICO measurements of $\mathrm{Os}_{3}(\mathrm{CO})_{12}$ - The 7-35 eV single ionization binding energy region. J. Chem. Phys. 2018, 148, 084301. [CrossRef]

120. Iatsunskyi, I.; Kempiński, M.; Jancelewicz, M.; Załęski, K.; Jurga, S.; Smyntyna, V. Structural and XPS characterization of ALD $\mathrm{Al}_{2} \mathrm{O}_{3}$ coated porous silicon. Vacuum 2015, 113, 52-58. [CrossRef]

121. Sharma, K.; Routkevitch, D.; Varaksa, N.; George, S.M. Spatial atomic layer deposition on flexible porous substrates: $\mathrm{ZnO}$ on anodic aluminum oxide films and $\mathrm{Al}_{2} \mathrm{O}_{3}$ on $\mathrm{Li}$ ion battery electrodes. J. Vac. Sci. Technol. A 2016, 34, 01A146. [CrossRef]

122. Haschke, S.; Pankin, D.; Petrov, Y.; Bochmann, S.; Manshina, A.; Bachmann, J. Design rules for oxygen evolution catalysis at porous iron oxide electrodes: A 1000-fold current density increase. ChemSusChem 2017, 10, 3644-3651. [CrossRef]

123. Xiong, S.; Yang, Y.; Zhong, Z.; Wang, Y. One-step synthesis of carbon-hybridized ZnO on polymeric foams by atomic layer deposition for efficient absorption of oils from water. Ind. Eng. Chem. Res. 2018, 57, 1269-1276. [CrossRef] 
124. Xu, D.; Wang, S.; Wu, B.; Huo, C.; Qin, Y.; Zhang, B.; Yin, J.; Huang, L.; Wen, X.; Yang, Y.; et al. Tailoring $\mathrm{Pt}$ locations in KL zeolite by improved atomic layer deposition for excellent performance in $\mathrm{n}$-heptane aromatization. J. Catal. 2018, 365, 163-173. [CrossRef]

125. Eswar, N.K.R.; Singh, S.A.; Heo, J. Atomic layer deposited photocatalysts: Comprehensive review on viable fabrication routes and reactor design approaches for photo-mediated redox reactions. J. Mater. Chem. A 2019, 7, 17703-17734. [CrossRef]

126. Cao, Y.; Wu, Y.; Badie, C.; Cadot, S.; Camp, C.; Quadrelli, E.A.; Bachmann, J. Electrocatalytic performance of titania nanotube arrays coated with $\mathrm{MoS}_{2}$ by ALD toward the hydrogen evolution reaction. ACS Omega 2019, 4, 8816-8823. [CrossRef]

(C) 2019 by the author. Licensee MDPI, Basel, Switzerland. This article is an open access article distributed under the terms and conditions of the Creative Commons Attribution (CC BY) license (http://creativecommons.org/licenses/by/4.0/). 